\title{
Is Mastectomy Still Justified - And if, in Which Patients?
}

\author{
Werner Audretsch ${ }^{\mathrm{a}} \quad$ Christoph Andree ${ }^{\mathrm{b}}$ \\ a Interdisciplinary Breast Center, \\ ${ }^{b}$ Department of Plastic and Reconstructive Surgery, Kliniken der Landeshauptstadt Düsseldorf, Germany
}

Breast surgery has evolved from simple to complex. Formerly, breast cancer was treated mainly by the radical Rotter-Halstedt operation, the most mutilating breast cancer surgery. Today, surgery has developed into an advanced and comprehensive treatment modality with many different options: mastectomy together with delayed or immediate reconstruction, quadrantectomy with axillary dissection and whole breast irradiation (QUART), skin-sparing mastectomy with immediate reconstruction or partial mastectomy.

The first step to more complexity was the mandatory addition of whole-breast radiotherapy (WBRT) in case of breast-conserving surgery (BCT) to reduce the local recurrence rate independently of oncological indications, such as lymph node involvement or tumor size. The evolution of radiation in 2006 reveals WBRT and partial breast radiotherapy (PBRT) together with better dosimetry and options of intraoperative radio therapy (IORT) [1], applicator intracavity radiotherapy (TARGIT) [2] and brachytherapy [3] or intensity modulated radio therapy [4]. Another step to more complexity was the addition of oncoplastic surgery to of breast conserving surgery, un-influential in terms of local control but powerful in preserving function and cosmetic outcome.

Now that we have all these options, why still perform mastectomy? The justification of mastectomy is powered by the contraindication of breast conserving surgery, the current surgical standard for breast cancer, i.e. pregnancy, previous breast irradiation, larger breast cancer, multicentric disease, inflamatory cancer, an extended intraductal component, very small breasts, collagen vascular disease or poor compliance for radiation treatment and most recurrences after BCT. As well, late results in young patients (therapeutic clearing, salvage intervention), subgroups with risk factors (prophylactic risk reduction) are indications for mastectomy.

The available techniques are: modified radical mastectomy with skin closure favorable to the supply with epi-prosthesis and reconstruction, skin-sparing mastectomy with different skin resection patterns, such as peri-areolar, tennis racket or inverted $\mathrm{T}$, subcutaneous mastectomy with preservation of the nipple areola complex (NAC) and flap-supported mastectomy. To obtain wide chest tissue and skin resection together with safe defect closure in locally advanced breast cancer after prior chemotherapy and/ or radiation flap-supported mastectomy can be combined with thoraco-epigastric flap (TEF), latissimus dorsi flap (LDF) or rectus muscle abdominal flap (TRAM). In combination with skin-sparing mastectomy, the most important autologous tools for reconstruction are TRAM, LDF and free-flap, in particular deep inferior epigastric perforator flap (DIEP). In addition, implants have been improved as cohesive gel and memory shape devices.

But what about function of the breast, i.e. cosmesis, psychology, and patient satisfaction? We are all familiar and experienced with total mastectomy reconstruction and we know about delayed post-radiation partial breast reconstruction for deformities and distortions appearing in about $20 \%$ of the true QUART cases. Coupled reconstruction in form of oncoplastic surgery $[5,6]$ is the strategy behind up-front tumor specific partial breast reconstruction which improves cosmesis in these $20 \%$. Oncoplastic surgery primarily has been developed to balance, even in cases with problems of relative tumor size and unfavorable anatomical tumor location, local control through clear margins and a cosmetic outcome.

So what can we currently offer our patients in terms of attempt at local control, function and cure? The straight-forward QUART is still considered simple and safe when targeted at loco-regional disease. With proper staging survival is comparable to modified radical mastectomy and to Halstedt. Compared to the easy and safe surgery of QUART or modified radical mastectomy with delayed reconstruction, skinsparing mastectomy together with immediate breast reconstruction is difficult and bears surgical risks.

\begin{tabular}{ll}
\hline KARGER & @ 2006 S. Karger GmbH, Freiburg \\
Fax +497614520714 & Accessible online at: \\
$\begin{array}{l}\text { E-mail Information@Karger.de } \\
\text { www.karger.com }\end{array}$ & www.karger.com/onk
\end{tabular}

a.r. Prof. Dr. med. Werner Audretsch Interdisziplinäres Brustzentrum - IBC Kliniken der Landeshauptstadt $\mathrm{gGmbH}$ Gräulinger Strasse 120, 40625 Düsseldorf, Germany Fax +49211 286696

E-mailw.audretsch@kliniken-duesseldorf.de 
Table 1. Indications for skin-sparing mastectomy

\begin{tabular}{|c|c|c|c|c|}
\hline Diagnosis & $\begin{array}{l}\text { BRCA carrier or } \\
\text { pure DCIS T1/2+ LCI }\end{array}$ & $\begin{aligned} & \text { early stage }=/<2 \mathrm{~cm} / \text { node } \\
& \text { negative } /<45 \mathrm{y}\end{aligned}$ & $\begin{array}{l}\text { more advanced }>2 \mathrm{~cm} / \\
3 \mathrm{~N}+/ \text { expected XRT or prior } \\
\text { whole breast irradiation }\end{array}$ & $\begin{array}{l}\text { prior partial or intraoperative } \\
\text { breast irradiation }\end{array}$ \\
\hline Options & SSM superior to SCM & avoid XRT & & \\
\hline Type of surgery & $\begin{array}{l}\text { SSM/ Implant/ autologous } \\
\text { tissue }\end{array}$ & $\begin{array}{l}\mathrm{SSM} / \text { extended LAT/ } \\
\mathrm{DIEP} / \text { implant }\end{array}$ & $\begin{array}{l}\text { SSM plus immediate } \\
\text { extended LAT/ temporary } \\
\text { expander followed by implant } \\
\text { or flap }\end{array}$ & $\begin{array}{l}\text { SSM plus implant/ autologous } \\
\text { tissue }\end{array}$ \\
\hline Controversial & no & $\begin{array}{l}\text { alternative to BCT for } \mathrm{t} \\
\text { the very young patient }\end{array}$ & $\begin{array}{l}\text { immediate pedicled TRAM/ } \\
\text { DIEP }\end{array}$ & no \\
\hline
\end{tabular}

BRCA: Breast cancer gene, DCIS: ductal carcinoma in situ, SSM: skin-sparing mastectomy, SCM: subcutaneous mastectomy, XRT: radiotherapy, LAT: latissimus dorsi flap, DIEP: deep inferior epigastric perforator, TRAM: transverse rectus abdominis muscle.

Currently, the advances in surgery and the refinements in radiation open a more complex but less evidence-based supply of individual options of local treatment of breast cancer to our patients. The oncological safety of skin-sparing mastectomy was neither compared to modified radical mastectomy nor Halsted nor QUART through prospective validation. The Oxford Level of Evidence (LOE) for oncological outcome can only be scored as 3 a based on systematic reviews with homogeneity or $3 \mathrm{~b}$ calculated from individual case-control studies. Therefore the Oxford Grade of Recommendation (GR) can only be given as $\mathrm{B}$, which means that this intervention has not shown validated benefit for patients and may be performed only in individual cases. According to the current knowledge a general recommendation cannot be given.

Subcutaneous mastectomy means leaving the NAC in place and removing the glandular tissue to an extend of $80-85 \%$. This technique has also not been validated on a higher level of evidence, neither for cancer treatment nor for complete risk reduction. A prospective randomized trial on nipple-sparing mastectomy including IORT for the areola complex [7] is in progress; but radiotherapy (RT) is a 'gift never forgotten'. The high number of the surgeons and gynecologists leaving the NAC behind in $73 \%$ on the basis of frozen section in the 'management of skin-sparing mastectomy' as a result of the survey of German hospitals [8] is surprising. This intervention should better be termed subcutaneous mastectomy than skinsparing mastectomy. Both skin-sparing and subcutaneous mastectomy are inevitably linked to immediate reconstruction by means of implants, autologous tissue, or a combination. The oncological and cosmetic outcome of skin-sparing mastectomy has been well evaluated during the past 30 years. In contrast, the outcome of the so called 'exchange mastectomy' i.e. subcutaneous removal of the gland and volume replacement with an implant, an intervention, very much favored in the 1970s in Germany and the USA, was characterized by a high number of revisions, up to 10 interventions for correction over
10 years. The results were aptly labeled 'subcutaneous mastectomy cripple' [9].

Skin-sparing mastectomy plus immediate reconstruction by DIEP is the most advanced and demanding intervention which requires a skilled team in oncology and reconstruction. An upfront planning of the comprehensive approach is highly recommended. All prior therapies, in particular local treatment modalities such as lymph node dissection and radiotherapy as well as the type of reconstruction and potential risk factors must be taken into account.

The high number of LDF in the German survey [8] reveals a common experience. Because of its twofold - either simultaneous or successive - availability and its paired occurrence, in which the LDF resembles the breast, this tissue replacement is the most important and best suited tool for any composed surgical approach to the breast as well as for volume and skin replacement. Transferred tissue, allowing local radical surgery, is considered healthy and free of tumor cells. Generally, radiotherapy is not indicated but if there is a justification for RT from an oncological point of view and not being applied prior to surgery, radiotherapy can also take place after LDF quadrantectomy reconstruction or in case of skin-sparing mastectomy. Independently of the reported good results, the high percentage of LDF reconstructions seems to be the result of 'oneeyed decision-making' based on a limited repertoire of reconstructive techniques. In view of the life-long consequences of the intervention, particularly in young patients the best possible technique should be chosen. The offer of skin-sparing mastectomy plus DIEP, i.e. reconstruction with healthy autologous tissue, and the possibility to avoid RT for a 'small' breast cancer in younger patients [10] is a significant change in the treatment of early disease to avoid increased local recurrences and probably unnecessary mortality in the long run [11]. On the other hand, IORT restricted to the tumor bed could open a safer window for sequential skin-sparing mastectomy plus reconstruction in case of in-breast tumor recurrence or lack in 
follow-up, because of the avoidance of radiotherapy strain to the skin.

We are still far from evidence-based guidelines but experts' opinion may allow a proposal for skin-sparing mastectomy as the 'gold standard' of breast removal (table 1). Prerequisites are a breast center that should allocate routinely up-front true multidisciplinary meetings (MDMs) concentrating on oncologic surgery, radio oncology and specific reconstruction to obtain the most convenient patient-centered treatment plan together with data collection for validation.

\section{References}

1 Bernier J, Viale G, Orecchia R, Ballardini B, Richetti A, Bronz L, Franzetti-Pellanda A, Intra M, Veronesi U: Partial irradiation of the breast: Old challenges, new solutions. Breast 2006 Jan 23, [Epub ahead of print]

2 Vaidya JS, Baum M, Tobias JS et al: Targeted intraoperative Radiotherapy (TARGIT) an inaovative treatment for early breast cancer. Ann Oncol 2001;12:1075-1080.

3 Das RK, Patel R, Shah H, Odau H, Kuske RR: 3D CT-based high-dose-rate breast brachytherapy implants: treatment planning and quality assurance. Int J Radiat Oncol Biol Phys 2004;59:1224-1228.

4 Arthur DW, Morris MM, Vicini FA: Breast cancer: new radiation treatment options. Oncology (Williston Park) 2004;18:1621-1629.
5 Audretsch W: Reconstruction of the partial mastectomy defect: classification and method; in Spear SL, Little JB (eds): Surgery of the Breast: Principles and Art, Lippincott-Raven, Washington 2005.

6 Benjamin O, Masetti R, Silverstein M, et al: Oncoplastic approaches to partial mastectomy: an overview of volume-displacement techniques. Lancet Oncol, 2005;6:145-157.

7 Petit JY, Veronesi U, Orecchia R, Luini A, Rey P, Intra M, Didier F, Martella S, Rietjens M, Garusi C, De Lorenzi F, Gatti G, Leon ME, Casadio C: Nipple-sparing mastectomy in association with intra operative radiotherapy (ELIOT): a new type of mastectomy for breast cancer treatment. Breast Cancer Res Treat 2006;96:47-51.
8 Dian D, Hemminger G, Janni W, Friese K, Jänicke F: Management of skin-sparing mastectomy: results of a survey of German hospitals. Onkologie 2006; 29:267-270

9 Pendergrast WJ Jr, Bostwick J 3rd, Jurkiewicz MJ: The subcutaneous mastectomy cripple: surgical rehabilitation with the latissimus dorsi flap. Plast Reconstr Surg 1980;66:554-559.

10 Kroman N, Holtveg H, et al: Effect of breast conserving therapy versus radical mastectomy on prognosis for young women with breast carcinoma Cancer 2004;100:688-693.

11 Early Breast Cancer Trialists Collaborative Group (EBCTCG): Effects of radiotherpy and of differences in the extend of surgery for early breast cancer on local recurrence and 15-year survival: an overview of the randomized trials. Lancet 2005;366: 2087-2106. 